\title{
Atypical Presentation as Unilateral Renal and Soft Tissue Metastases from Follicular Carcinoma Thyroid
}

\author{
Ambikavathy Mohan, S Kumar, Udaya Kumar
}

\begin{abstract}
Thyroid carcinoma comprises $1 \%$ of all malignancies. Follicular thyroid carcinoma is the second most common cancer of thyroid. Vascular invasion and hematogenous metastases to bone, lungs, brain, skin and adrenal glands has a reported incidence of 11 to $25 \%$. The initial presentation of the patient with distant metastases is rare. Well-differentiated thyroid cancers with renal secondaries are reported in limited number of cases so far. We report a case of an asymptomatic female patient who presented to us with soft tissue metastases to scalp, left scapular region and left kidney. On further evaluating, ultrasound of the neck showed a solitary nodule of $2 \times 1 \mathrm{~cm}$ in the left lobe of thyroid. Fine needle aspiration cytology (FNAC) of thyroid reported as follicular carcinoma. FNAC of scalp, scapular swelling, and left kidney lesion was reported as metastatic lesions from follicular thyroid cancer. The patient refused any surgical intervention and she received three cycles of chemotherapy and suppressive treatment with L-thyroxine. She is on regular follow-up with the stable disease till date. We present this case for its rarity of renal metastases from follicular thyroid cancer.
\end{abstract}

Keywords: Follicular thyroid cancer, Renal metastases, Soft tissue metastases.

How to cite this article: Mohan A, Kumar S, Kumar U. Atypical Presentation as Unilateral Renal and Soft Tissue Metastases from Follicular Carcinoma Thyroid. Int $\mathrm{J}$ Head and Neck Surg 2012;3(3):184-186.

\section{Source of support: Nil}

\section{Conflict of interest: None}

\section{INTRODUCTION}

Follicular thyroid cancers are more aggressive than the papillary thyroid cancers due to the vascular invasion. Patients presenting with metastases to soft tissues and kidney, in the absence of goiter, are rare. Literatures have reported cases of follicular thyroid cancers with renal metastasis in autopsy specimens and those during life are few with an incidence of 4.5 to $5.9 \% .{ }^{1-3} \mathrm{We}$ report this case for its rarity of presentation.

\section{CASE REPORT}

An elderly female patient aged 58 years, who was otherwise normal, was presented to surgical outpatient with history of a painless swelling in the right occipitoparietal region from 1 year with recent increase in size. On clinical examination, the swelling of size $6 \times 4 \mathrm{~cm}$ was present in the right occipitoparietal region, warm, nontender, soft and pulsatile. The underlying skull bone was deficient. A swelling over the left scapular region was seen of size $12 \times 8 \mathrm{~cm}$ nontender, fixed and firm (Figs 1 and 2). Thyroid region appeared normal. Clinically follicular thyroid cancer with soft tissue metastases was made and she was further evaluated.

Ultrasound neck picked up a solitary nodule in the left lobe of thyroid of size $2 \times 1 \mathrm{~cm}$. Fine needle aspiration cytology (FNAC) of thyroid and soft tissue swellings confirmed follicular neoplasm with metastases (Figs 3 and 4). X-ray of the skull showed a soft tissue swelling with underlying bone erosion (Fig. 5) and that of the lumbosacral spine with pathological fracture. Ultrasound abdomen reported a left renal lesion in the upper pole of size $2 \times 3 \mathrm{~cm}$, the aspiration cytology confirmed follicular metastases to kidney. A computed tomographic (CT) scan abdomen imaged the left renal lesion (Fig. 6). FNAC of the renal

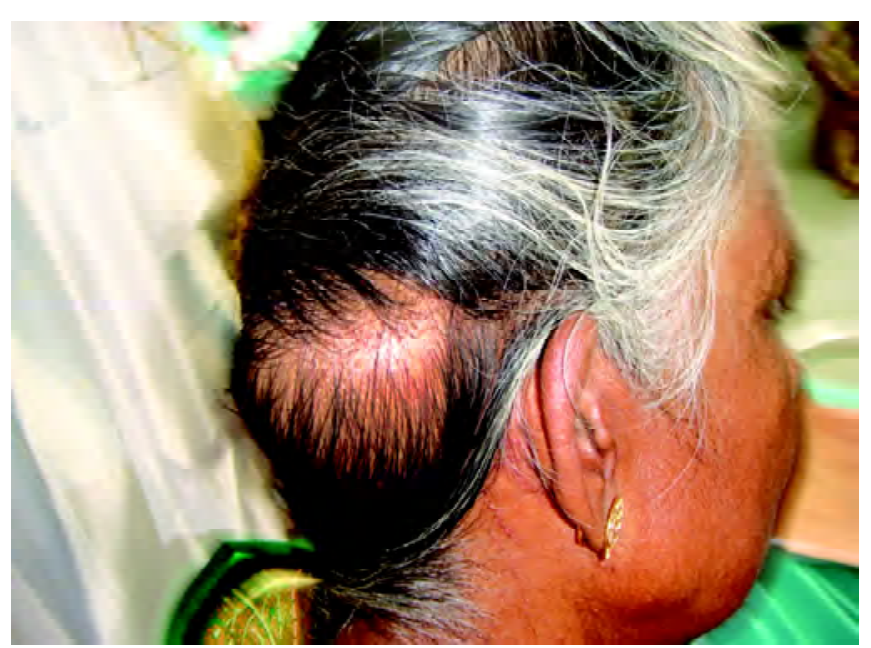

Fig. 1: Patient with right occipitoparietal swelling

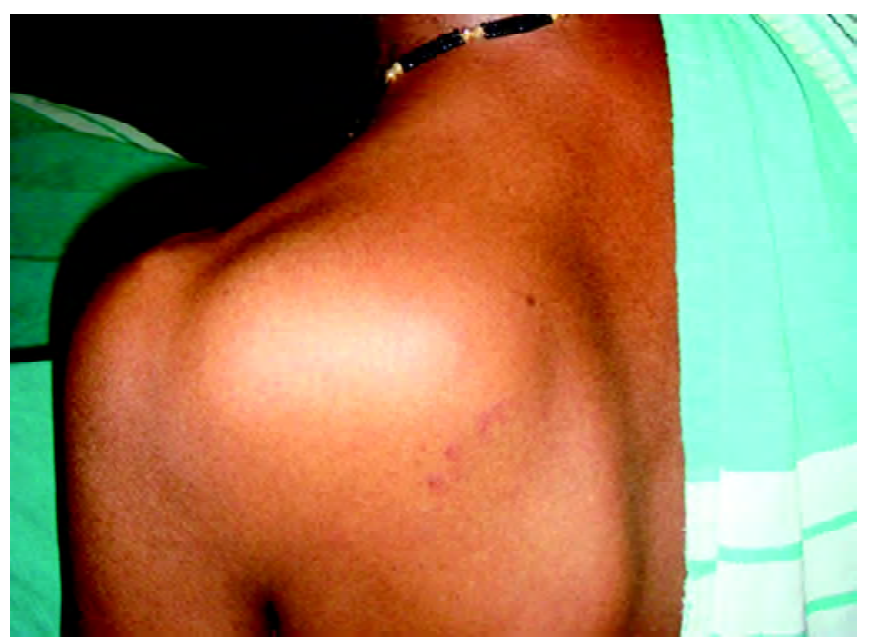

Fig. 2: The patient with soft tissue swelling over left scapular region. The right occipitoparietal swelling is also seen 
mass, scalp and soft tissue swelling over left shoulder and the thyroid swelling showed thyroid follicular cells arranged in microfollicular pattern. The cells showed mild nuclear pleomorphism and coarse chromatin with scanty eosinophilic cytoplasm. The colloid was absent (Figs 3 to 4$)$. Thyroglobulin estimation was markedly raised to 2,300 ng/ml.

The patient was counselled for a definitive surgery that is total thyroidectomy and left nephrectomy and as she refused any intervention chemotherapy was given with suppressive L-thyroxine. The patient is on regular follow-up till date with stable disease.

\section{DISCUSSION}

Follicular thyroid cancer is the second commonest neoplasms of thyroid. Being aggressive metastases is through hematogenous spread. Patients in the 4th and 5th decade can present with features of distant metastases to soft tissue, bone, brain and renal and adrenals ${ }^{1,3}$ in the absence of a thyroid swelling, as seen in our patient. In about $80 \%$ of the cases a solitary nodule is usually noticed, however, in $20 \%$ of patients distant metastases is reported in literature. ${ }^{2-4}$

Renal metastases are usually multiple and bilateral in the presence of extensive disease. ${ }^{6}$ Our patient had an isolated lesion in the left kidney; probably the spread was through minor lymphatics or venous spread. ${ }^{6}$

Treatment of such cases presenting with distant metastases is of multimodality. Total thyroidectomy for the primary tumor is done if resectable. ${ }^{1,3}$ Radioactive iodine therapy with suppressive L-thyroxine was given for metastatic well-differentiated cancers. ${ }^{4,8}$ Surgical removal of resectable metastatic lesions helps as a debulking procedure, however, the quality of life and prognosis following such complicated surgeries are to be weighed upon. ${ }^{5,9,10}$ Bone metastases require external beam radiotherapy. ${ }^{3,7}$ Our patient was not willing for any intervention except for chemotherapy and suppression eltroxin.

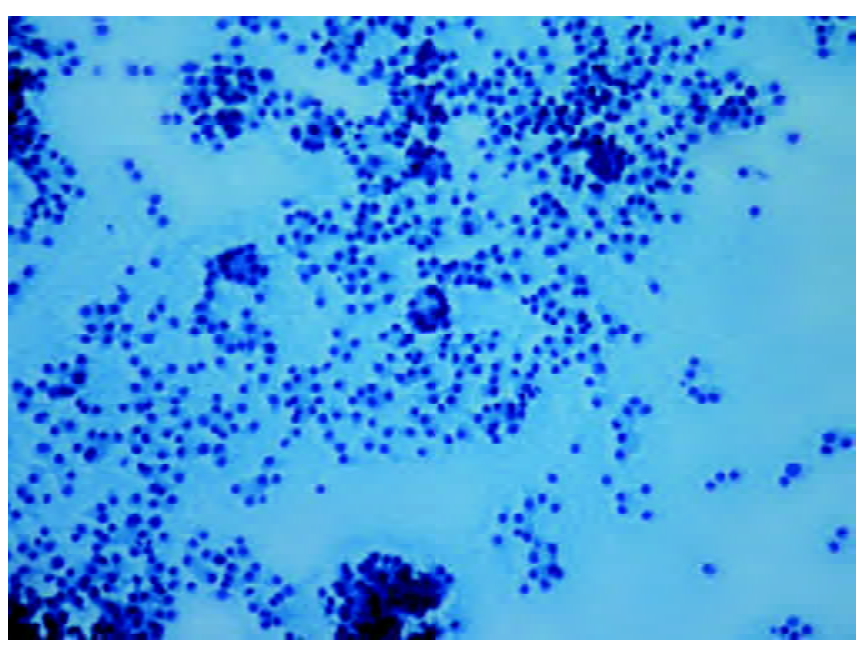

Fig. 3: Microphotograph showing microfollicular pattern on Papanicolaou stain (magnification $\times 40$ )

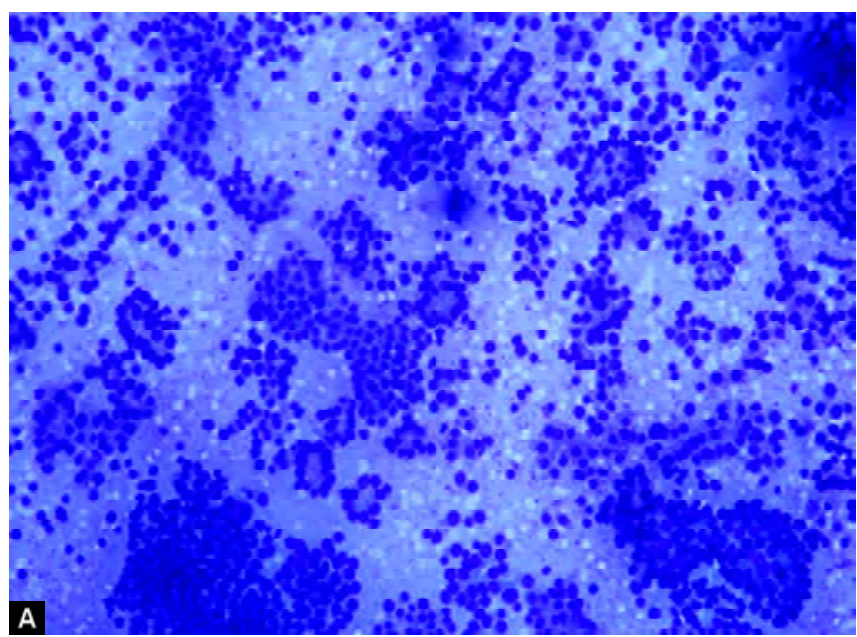

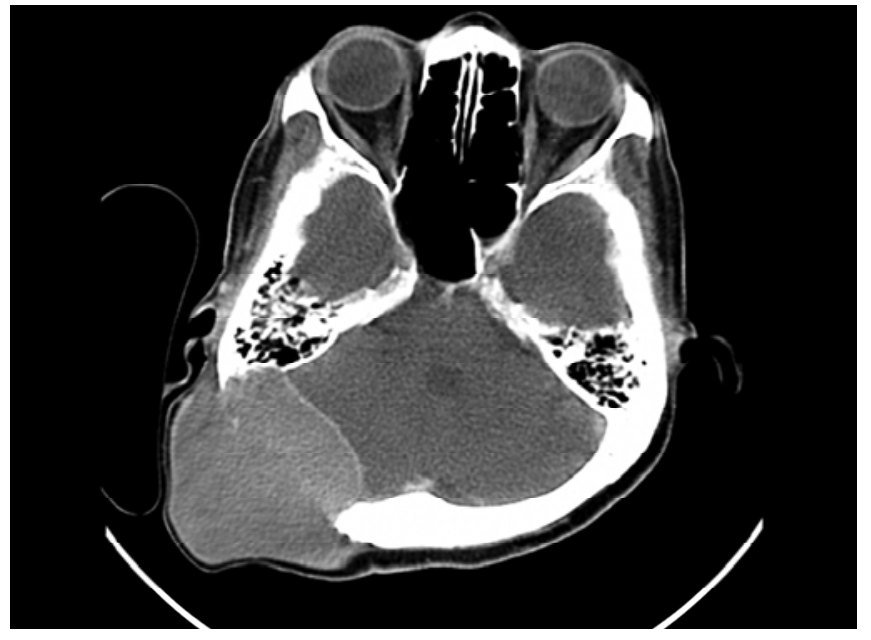

Fig. 5: CT image of brain showing soft tissue lesion with bone erosion

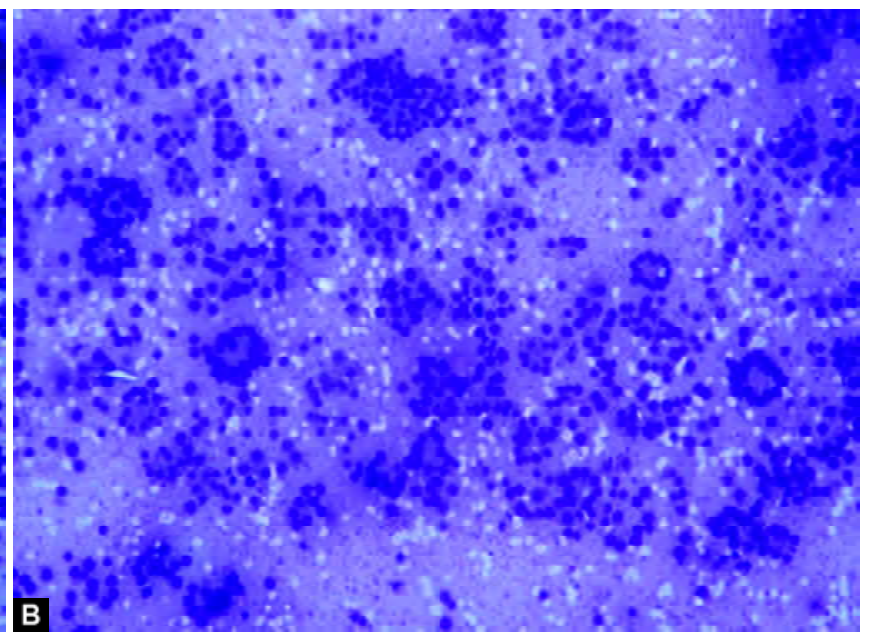

Figs 4A and B: Microphotographs (MGG stain $\times 40$ ) with thyroid follicular cells with mild anisokaryosis and coarse nuclear chromatin arranged in microfollicular pattern 


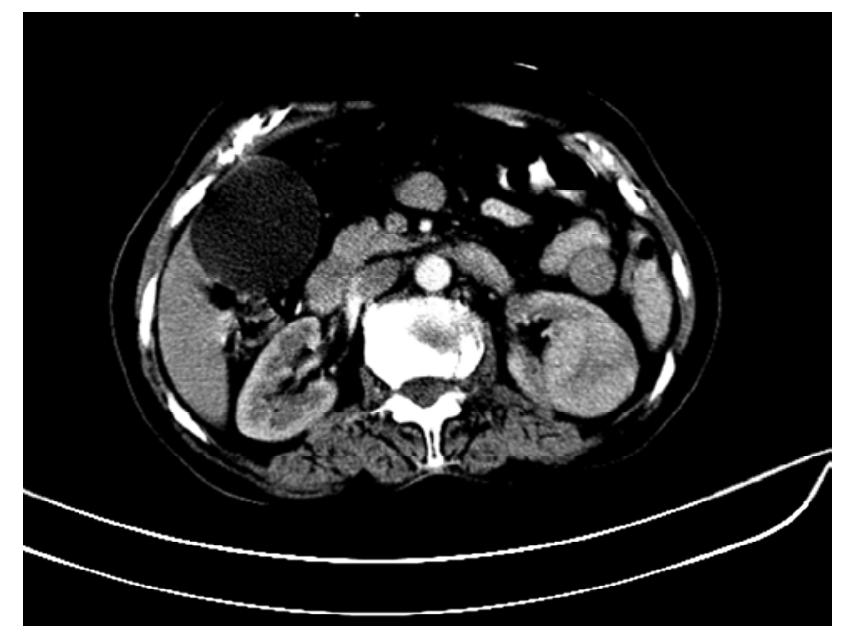

Fig. 6: CT image of abdomen (cross-section) showing tumor in the left kidney

\section{CONCLUSION}

Patients with follicular thyroid cancers may be asymptomatic or present with features of distant metastases, such as soft tissue and renal involvement, therefore, a thorough workup of the patient with USG, CT/MRI imaging is required to diagnose occult metastases.

\section{REFERENCES}

1. Shaha AR, Shah JP, Loree TR. Differentiated thyroid cancer presenting initially with distant metastases. Am J Surg 1997; 174:474-76.

2. Heitz P, Moser H, Stuab JJ. Thyroid cancer: A study of 573 thyroid tumors and 161 autopsy cases observed over a 30 years period. Cancer 1976;37:2329-37.

3. Siliphant WM, Klinck GH, Levitin MS. Thyroid carcinoma and death: A clinicopathological study of 193 autopsies. Cancer 1964;17:513-25.
4. Balasubramanian SP, Thomas WEG. Thyroid neoplasms (including the solitary nodules). Surgery 2007;25:482-86.

5. Takayasu H, Kumamoto Y, Ueno A. A case of bilateral metastatic renal tumour originating from a thyroid carcinoma. J Urol 1968;100:717-19.

6. Lucke B, Schlumberger HG. Tumors of the kidney, renal pelvis, and ureter. In: Atlas of tumor pathology. Washington, DC: Armed Forces Institute of Pathology 1957:137-45.

7. Wagle DG, Moore RH, Murphy GP. Secondary carcinomas of the kidney. J Urol 1975;114:30-32.

8. Guidelines for the management of thyroid cancer (2nd ed). British thyroid association. London: Royal College of Physicians 2007 Aug.

9. Maxon HR. Quantitative radioiodine therapy in the treatment of differentiated thyroid cancer. Quarterly J Nuc Med 1999;43: 313-23.

10. Niederle B, Roka R, Schemper M, et al. Surgical treatment of distant metastases in differentiated thyroid cancer: Indication and results. Surgery 1986;100(6):1088-97.

\section{ABOUT THE AUTHOR}

\section{Ambikavathy Mohan}

Assistant Professor, Department of Surgery, SDUMC, Kolar Karnataka, India, e-mail: ambikashri67@live.com

\section{S Kumar}

Associate Professor, Department of Medicine, Sri Devaraj Urs Medical College, Kolar, Karnataka, India

\section{Udaya Kumar}

Professor, Department of Pathology, Sri Devaraj Urs Medical College Kolar, Karnataka, India 